\title{
The Errors and Solutions on C-E Translation of Environmental Protection-Related Signs Guided by Functional Equivalence
}

\author{
Wang Cai-ying \\ Quanzhou Normal University, P. R. China \\ E-mail: 804028787@qq.com \\ Dai Congjie \\ Quanzhou Normal University, P. R. China \\ E-mail: congjiedai501@163.com
}

Received: March 5, 2018 Accepted: April 4, 2018 Published: April 5, 2018

doi: 10.5296/jsss.v5i2.12952 URL: http://doi.org/10.5296/jsss.v5i2.12952

\begin{abstract}
With the growing concern about the environment protection, environmental protection-related signs are ubiquitous in China now. This paper first introduces the relevant concepts about functional equivalence, analyzes the errors and mistakes in Chinese-English translation of environmental protection-related signs and proposes some feasible solutions. Common errors in translations in question include linguistic errors, cultural errors and pragmatic errors which generally result from cultural discrepancy, the translators' incompetence and the initiators' carelessness. Some solutions like lexicon equivalence, semantic equivalence, syntax equivalence, discourse equivalence are proposed to solve these problems.
\end{abstract}

Keywords: Environmental protection-related signs, Errors, Functional equivalence, Solutions

\section{Introduction}

Environmental protection and sustainable development have become one of the highly-charged concerns in the world. Just as other kinds of public signs, environmental protection-related signs play a pivotal role in summoning people's awareness of environmental protection and guiding people to protect the environment. In recent years, with 
the increasing exchanges with foreign countries, heaps and heaps of foreign friends have come to China and public signs facilitate their living, working and playing in China. Due to various reasons, errors and mistakes are committed in the C-E translation of environmental protection-related signs.

This paper expounds the errors and mistakes of environmental protection-related signs and some solutions are put forward under the guidance of functional equivalence.

\section{The Relevant Concepts}

The definition of "sign" given by New Oxford Dictionary of English (2001) is "A notice that is publicly displayed giving information or instruction in a written or symbolic form." Environmental protection-related signs are those signs related to protect the environment. Reiss classified the texts into three types: informative, expressive and operative (Reiss, 2000). Environmental protection-related signs can be grouped into informative and/or operative text types. According to the theories of Reiss' and Munday, the characteristic of informative signs is plain communication of facts and the translation method should be in "plain prose", without redundancy and with the use of explanation when required. The characteristic of operative signs is "inducing behavioral responses". The form of language is dialogic, the focus is appellative, and therefore the translation method should employ the "adaptive" method, creating an equivalent effect among target language readers (Zhang, 2015).

The common feature of English and Chinese public signs is concise. English public signs are concise and expressive, while Chinese public signs feature four-character idioms, adjectives, conventional expressions, jargon and likewise. Balanced sentences, which consist of two parts of the same structure and roughly the same length, and with contrasted (or similar) ideas, can often be found in Chinese public signs. Generally speaking, Chinese public signs are poetic and English ones are apt to clear and concise.

The functions of environmental protection-related public signs are to raise people's awareness of environmental protection, regulate people's social behavior, optimize the quality of life and construct peaceful society.

"Translating consists in producing in the receptor language the closest natural equivalent of the source language message, first in terms of meaning and secondly in terms of style. Translating means translating meaning." (Nida \& Taber, 1969). In the succeeding decades, he developed, modified and supplemented his theory. In Nida's book From One Language to Another, "functional equivalence" was initially used as a substitute for dynamic equivalence. Functional equivalence is "not only the equivalent content of message, but, in so far as possible equivalent of the form." "Equivalence' cannot be understood in its mathematical meaning of identity, but only in term of proximity, i.e., on the basis of degrees of closeness to functional identity." (Nida, 2001). That is, the translation is not a simple transformation of words, sentences or texts, but to achieve functional equivalence between the two languages. It can convey full meaning of the source texts and can be understood fully and smoothly by the target readers who have the similar or identical response. Generally speaking, functional equivalence constitutes four aspects: lexicon, syntactic, discourse and stylistic. 


\section{Literature Review}

At present, the theories applied to the translation of public signs mainly include Functional Equivalence, Text Typology, Scopos Theory, Pragmatics, Receptional Aesthetic, Eco-translatology and so on. Some scholars pointed out the errors and mistakes in the C-E translation of public signs and also suggested some solutions.

Public signs are partly integrated with linguistic landscape. It examines the presence of English language in 'public road signs, advertising billboards, street names, place names, commercial shop signs, and public signs on government buildings' (Landry \& Bourhis, 1997). Shohamy and Gorter (2009) describe linguistic landscape as 'language in the environment, words and images displayed and exposed in public spaces'. Wan (2016) identified four kinds of errors (Chinese English, spelling mistakes, grammar errors and improper use of words), analyzed three reasons (culture differences, translators' personal factors and social factors) for mistranslating the public signs and suggested two solutions to improve the quality of the translation of public signs in tourism spots.

\section{Research Method}

The examples in this paper are from http://image.baidu.com/, some scholars' papers or photos taken by myself in the downtown of Quanzhou city.

\section{The Errors and Solutions of Environmental Protection-Related Signs}

\subsection{The Causes of the Errors and Solutions}

\subsubsection{The Cultural Discrepancy}

The definition of culture given by Oxford English Dictionary is "the beliefs and attitudes about something that people in a particular group or organization share". Peter Newmark defined culture as "the total range of activities and ideas and their material expression in objects and processes peculiar to a group of people, as well as their particular environment" (Peter, 1988). Different regions and countries have their own cultures, so cultural differences emerge. Culture differences involve different politics and law, language, art, values, customs, religious, beliefs and lifestyles and so on. Cultural discrepancy results in interpreting the same expressions differently. Difficulties in translation arise when there is little or no awareness of the above-mentioned divergent cultural elements.

\subsubsection{The Translators' Competence}

To become a qualified translator, the translators should not only have a serious and meticulous working attitude, but also have at least five basic qualities: sound bilingual knowledge, abundant cultural background knowledge, the relevant professional knowledge, the ability to use translation tools and online resources, the ability of creativity. However, many errors and mistakes stem from the translator's incompetence.

\subsubsection{The Government Management}

The relevant department is not in charge of the translation, examination and the sign making, 
what is worse, no professional department is established in some cities to provide such services.

\subsubsection{The Initiators}

Some initiators lay little emphasis on the translation of public signs, and they have little understanding of translation activity so that they just translate the public signs by translation software or ask someone who has learnt English before or known a little English. The translated versions are not proofread by himself or the professional department which is in charge of translation, examination and the sign making.

\subsection{The Errors and Mistakes of Environmental Protection-Related Signs}

\subsubsection{Linguistic Mistakes}

\subsubsection{Chinese pinyin}

Pinyin, also known as Chinese phonetic alphabet, characterizes the pronunciation of Chinese characters. However, Chinese and English have their own spelling rules and linguistic norms, “可回收物” (ke huishou wu) and “不可回收物” (buke huishou wu) plus their Chinese pinyin "KE HUI SHOU WU" "BU KE HUI SHOU WU" is meaningless to those target readers who know little about Chinese.

\subsubsection{Mix-Using Chinese Pinyin and English}

“芳草妻萋, 踏之何忍” (fang cao qi qi, ta zhi he ren) is translated into “Fangcao qiqi riding the heren" which mixed Chinese pinyin with English. "Fangcao qiqi" is the Chinese pinyin of “芳草妻莾” (fang cao qi qi) and “heren” is the Chinese pinyin of"何忍” (he ren) ."riding the” is the word-for-word translation of “踏之” (ta zhi). This translation can't provide the information of the source text to the target readers and obviously fails to achieve the function of the public sign.

\subsubsection{Chinglish}

Hilarious and ridiculous Chinglish mistakes are often encountered in Chinese bilingual public signs. “踏入想一想, 小草也在长” (ta ru xiang yi xiang, xiao cao ye zai zhang) is translated into "INTO THE THINK GRASS IS LONG". This random translation didn't convey the meaning of Chinese public sign which tells the visitors to keep off the grass.

ST:“让我们做鸟类的朋友” (rang women zuo niao lei de pengyou)

TT: "Let us do the birds friend".

Regardless of the singular form of "friend", the birds should be changed into "birds", and it is obvious that the translated version is Chinglish, a form of written or spoken English negatively influenced by the Chinese language, culture or contexts. Oxford English Dictionary defines it as a mixture of Chinese and English, especially a variety of English used by speakers of Chinese or in a bilingual Chinese and English context, typically incorporating some Chinese vocabulary or constructions, or English terms specific to a Chinese context (Ding \& Wu, 2011). 


\subsubsection{Improper Use of Words}

“不要因你的美丽伤了我” (buyao yin ni di meili shangle wo) is translated into “Don't hurt me for your pretty." "Hurt" means "to injure oneself or someone else or to cause pain in a part of one's body" or "to feel pain in part of one's body". And when used as a noun, "pretty" means "a nice and attractive girl". This translation is a typical word pseudo-equivalence which is a superficial equivalence without fully comprehending and interpreting the Chinese public sign. The misuse of words "hurt" and "pretty" is not in accord with English linguistic norms. Without a good command of Chinese and English, "Don't hurt me for your pretty." not only didn't transmit clear and correct meaning of “不要因你的美丽伤了我” (buyao yin ni di meili shangle wo) in Chinese specific setting, but also cause misunderstanding to the target readers. What's worse, it leaves a negative impression on foreigners.

\subsubsection{Syntax Errors}

Syntax errors may arise from the translators' poor English or machine translation, which make the target readers fail to get the clear and full meaning from the public sign. "Grass and Flower, No Trampled please” which is the translation of “青青绿草, 请勿践踏” (qingqing lv cao, qing wu jianta) is a pseudo-equivalent translation. Grammatically speaking, "no" is an adjective which can't modify "trampled". The translated version "THE GRASS IS SMILING AT YOU. PLEASE DETOUR.”of “小草微微笑 请您旁边绕” (xiao cao weiwei xiao qing nin pangbian rao) is also a pseudo-equivalent translation. Because the translator lacks target language competence. According to Bachman (1990), language competence constitutes two parts: organizational competence and pragmatic competence. Although "THE GRASS IS SMILING AT YOU. PLEASE DETOUR." is in accordance with grammar rules and discourse, the incompetent translator still goes against pragmatic rules, neglecting the features and characteristics of public signs.

\subsubsection{Cultural Mistakes}

Each country has their own culture. Chinese and English public signs are rooted in their culture so that they are imprinted with a deep culture. “严禁吸烟” (yanjin xiyan) is ubiquitous in China which reminds people not to smoke in the place. If translated into "Don't smoke", the tone of this public sign may be rude. Because the tone of Chinese public signs lies on the readers as a whole, while the tone of English public signs is on the individual reader. Consequently, "No" deserves the first priority to express the negative action instead of "Don't" which is suitable in English culture. "No smoking" is the suggested version.

\subsubsection{Pragmatic Failures}

Pragmatic failure is "failure to achieve the desired communication effect in communication". (He, 1988) “减废回收最环保, 污者自费齐赞好。” (Jian fei huishou zui huanbao, wu zhe zifei qi zan hao) is a public-spirited sign in Macau. If literally translated into "Reducing and retrieving wastes are most environmental protection, making the polluters paid is praised by all." it is wordy which violates the principle of conciseness and may fail to achieve the objective of Chinese public sign. "Reduce Waste. Make Polluters Pay." Although there is no equivalence between the source language and the target language in the number of words, 
while it omits the evaluative words (“最环保” (zui huanbao), “齐赞好” (qi zan hao)) and only reserves the main theme of Chinese public sign, calling on the public to reduce waste or the polluters will be fined (Wang, 2009). “提倡节约, 反对浪费” (Tichang jieyue, fandui langfei) is a public sign in a middle school in Quanzhou, which is translated into "Promote the economy, the objection wasted". This English version also violates the native's expressive habits, so it is the unacceptability of the use of language which leads to the failure to achieve the expected effect.

\subsection{The Solutions}

\subsubsection{Lexicon Equivalence}

According to COLLINS COBUILD ADVANCED LEARNER'S ENGLISH-CHINESE $D I C T I O N A R Y$, Lexicon is defined as "the words associated with a particular subject." “一次 性用品” in the supermarket (CENTURY MART) refers to those products which can be only used once while its English version is a word-for-word version. "A TIME SEX THING" is the misuse of the words which will not transmit the full meaning of the original text, what's worse, it will result in misunderstanding. The suggested version should be "Disposable Products".

“芳草妻萋, 踏之何忍” (fang cao qi qi, ta zhi he ren) is translated into “Fangcao qiqi riding the heren" which mixed Chinese pinyin with English which will puzzle the target readers,because Chinese pinyin and English are different from each other,what's more, “riding the” isn’t the equivalent English of “踏之”(ta zhi). Apparently, it makes no sense for the foreigners. This example is the worst one which can't make the target readers get the correct information and devastate the Chinese image.

\subsubsection{Semantic Equivalence}

Leech (1974) once classified the semantics of words into 7 kinds:conceptual meaning, connotative meaning, stylistic meaning, affective meaning, reflected meaning, collocative meaning, thematic meaning. Improper word diction is often found in C-E translation of Chinese public signs. When we translate Chinese public signs, we may achieve accuracy and appropriateness by bearing the accurate comprehension of the original and the target readers' acceptance in mind.

“可回收垃圾” (ke huishou wu) and“不可回收垃圾” (buke huishou wu) are translated into "can be reused rubbish" "can't be reused rubbish". The conceptual meaning of "use" is "to do something with a machine, a method, an object, etc. for a particular purpose" and its connotative meaning is "to take a particular amount of a liquid, substance, etc. in order to achieve or make sth.” (Oxford Dictionary) However,“可回收垃圾”(ke huishou wu) or“不可 回收垃圾” (buke huishou wu)refers to the materials can be reused after being disinfected and processed from the rubbish. "recyclable" means "can be processed and used again." It is important for the translator to identify the basic meaning and deep meaning (conceptual meaning and associative meaning) of each word and select the most appropriate word in a certain context. The suggested versions of “可回收垃圾” (ke huishou wu) and “不可回收垃 圾”(buke huishou wu) are "Recyclables" and "Non-recyclables". 


\subsubsection{Syntactic Equivalence}

Syntax is the way that words and phrases are put together to form sentences in a language or the rules of grammar for this (Oxford English Dictionary). Since Chinese and English are of two different language systems, each language has its own different syntax rules in which Chinese sentences are inclined to be loose, using flowery words and various rhetoric, while English sentences are prone to be concise and logical with phrases and clauses.

“业务受理台” (yewu shouli tai) is a Chinese designative sign with a commonly-used character “台”(tai). "Business Reception Desk” will make the readers misunderstand the original meaning of this Chinese public sign which means the customers can receive the services here. "Desk" here is redundant word or an unnecessary word because of the differences between English syntax and Chinese syntax. The syntactic form should be adjusted to comply with the syntactic rule of target language, consequently, "Reception" and "Services" are acceptable versions in the English-speaking countries.

\subsubsection{Discourse Equivalence}

The text/discourse is a unit of language usage. Therefore, we should not only analyze the language itself in discourse analysis, but also know how language embodies meaning and function in a particular context. Discourse equivalence includes three levels: context, context of situation and culture. Different thinking modes lead to different Chinese and English texts. When translating, the translator should employ some proper methods to narrow the differences. The following is a good example.

The announcement posted in the railway station by British people who built the Shanghai-Nanjing Railway read: “随地吐痰, 最为恶习。既惹人厌, 又碍卫生。车站月台, 尤须清洁, 倘有违犯, 面斥莫怪。” (Suidi tu tan, zuiwei exi. Ji re ren yan, you ai weisheng. Chezhan yue tai, you xu qingjie, tang you weifan, mian chi mo guai.) and its English version is "IN THE INTEREST OF CLEANLINESS AND PUBLIC HEALTH PASSENGERS ARE REQUESTED TO REFRAIN FROM SPITTING IN THE TRAINS OR WITHEN THE STATAIN PREMISES." This Chinese public sign features four-character phrases with strong sense of rhythm, while the English version only retains the core meaning (no spitting in the trains or within the station premises)with plain language (Yang, 2005).

\subsubsection{Stylistic Equivalence}

ST: 小草微微笑, 请您旁边绕。(xiao cao weiwei xiao qing nin pangbian rao)

TT: THE GRASS IS SMILING AT YOU, PLEASE DETOUR.

The Chinese sign is composed of two parallel structures with personification (小草微微笑 [xiao cao weiwei xiao]) and end rhyme (笑 xiao; 绕 rao), reminding people not to trample the grass. Although there is no grammar error in this translation, the foreigners may still be confused because of the word-for-word translation and lack of semantic coherence. Some public signs already have a conventional translation. Therefore, "Keep off the grass" or "Please give me a chance to grow" can be borrowed. The second version "Please give me a chance to grow" retains the personification rhetoric in the source language and arouses 
people's affection and attention. What's more, this version preserves and highlights the original image of the source language.

ST: 小草正在休息请勿打扰。(xiao cao zhengzai xiuxi qing wu darao)

TT:"Please take care of the sleeping grass".

The translator endeavors to keep the personification in English version, while just as mentioned in the above example, personification in Chinese public sign only reminds people not to trample the grass. "The sleeping grass" is a confusing and absurd version which can't convey the proper meaning in Chinese public sign. "Please give me a chance to grow" is a suitable version for this sign to equal the style of the original one.

ST:小草正在休息请勿打扰。(xiao cao zhengzai xiuxi qing wu darao)

TT: "Please take care of the sleeping grass".

The translator endeavors to keep the personification in English version,while just mentioned in the above example,personification in Chinese public sign only reminds people not to trample the grass. "The sleeping grass" is a confusing and absurd version which can't convey the proper meaning in Chinese public sign. "Please give me a chance to grow" is a suitable version for this sign to equal the style of the original one. (This paragraph is the same as the above paragraph in the publication version)

\subsubsection{Pragmatic Equivalence}

Koller proposed the notion of pragmatic equivalence, regarding translation as a communicative activity to communicate the author's intention and meet the readers' need.

ST: “XX是我家, 清洁靠大家” (XX shi wojia, qingjie kao dajia)

TT: XX is our home, so each of us should keep it clean"

There is no word or grammar error in this translated version, but the problem is self-evident. It is rather wordy and clumsy, violating the rule of conciseness of the public sign. The revised version can be "Keep XX tidy, please."

ST: 保护一池碧水 营造一片宁静。(baohu yi chi bishui yingzao yipian ningjing)

TT: "The protection of a pool of clear water, creating a quiet".

The English version is the violation of the pragmatic principle - propriety. Obviously, it is a pragma-linguistic failure which non-native speakers endow an utterance a different pragmatic meaning from what a native speaker does? "The protection of a pool of clear water, creating a quiet" is a pragma-linguistic failure which doesn't comply with the conventional usage of English. The translator tries to semantically and syntactically equal the structures between the source language and the target language. On the other hand, the word-for-word transference is hardly acceptable to the foreigners, and it should be corrected into "Please keep the water clean" to achieve the communicative effect.

ST: 向前一小步, 文明一大步 (xiang qian yi xiao bu, wenming yi da bu) 
TT: A small step forward, a big step in civilization.

It is obvious that the English version is a machine translation. Besides word mistakes and grammar mistakes, it can't transmit the real meaning of Chinese public signs in the specific context. 向前一小步, 文明一大步 (xiang qian yi xiao bu, wenming yi da bu) is a public sign placed in the men's toilets to remind them not to make the ground dirty. The suggested version is "Please keep the toilet clean".

\section{ST:保护树木，爱护花草。(baohu shumu, aihu huacao)}

TT: Protect trees and cherish flowers and plants.

The English version ignores the implicit meaning of Chinese public signs. Literal translation of the Chinese public sign can't convey the real meaning or intention of the original text. "Please protect the environment" can not only convey the implication of its context but also avoid generating the pragmatic errors.

\section{Discussions}

As people's awareness of environmental protection continues to raise, an increasing number of bilingual environmental protection-related public signs have been designed. Errors and mistakes in public sign translations not only fail to perform the functions of public signs, but also devastate China's international image. Various mistakes found in C-E translation of public signs may result from the cultural discrepancy, the incompetent translators, lack of the management of the supervision department and the initiators' inability to control the quality of translation. The good translated versions should comply with the lexical equivalence, semantic equivalence, syntactic equivalence, discourse equivalence, stylistic equivalence and discourse equivalence.

The solutions are as follows: From the translators' perspective, the most important thing is that they should understand the language features and stylistic features of English and Chinese public signs, the translation principle and cultural discrepancy. Second, they should achieve good linguistic competence in both Chinese and English. Third, the translator should take the translation activity seriously. From the government perspective, a professional department should be established to supervise and examine the sign making and the translation of public signs. From the initiators' perspective, they should entrust the translation work to qualified translation companies or professionals and then the translated version should be sent to the relevant government's supervision department for quality control or supervision.

\section{Funding and Acknowledgement}

We are grateful to 'The Innovative Pragma-rhetoric Team Programme of Huaqiao University' (2018007), 'Apple-Reading Seminar of Huaqiao University' (18YJG57), 'Pragma-translatology of Huaqiao University's Education Reform' (18YJG07), “On Computer-Based English Writing Teaching for English Majors 2016012" and "Research on the Textbooks of Business English Writing for Undergraduates” (SKJYKT-185). 


\section{Macrothink}

Journal of Social Science Studies

ISSN 2329-9150 2018, Vol. 5, No. 2

\section{References}

Bachman, L. F. (1990). Fundamental consideration in language testing. Oxford: Oxford University Press.

Ding, W. D., \& Wu, B. (2011). A Basic Course in Writing. Beijing: Higher Education Press, the third edition.

Grofficy, L. (1974). Semantics: The study of meaning. London: Penguin Books Ltd.

He, Z. R. (1988). A Survey of Pragmatics. Changsha: Hunan Education Press.

Katharina, R. (2000). Type, Kind and Individuality of Text: Decision Making in Translation. In L. Veunti (Ed.), The Translation Studies Reader. London and New York: Routledge.

Landry, R., \& Richard, Y. B. (1997). Linguistic landscape and ethnolinguistic vitality: An empirical study. Journal of Language and Social Psychology, 16(1), 23-49. https://doi.org/10.1177/0261927X970161002

Peter, N. (2001). A Textbook of Translation. Shanghai: Shanghai Foreign Language Education Press.

Shohamy, E. G., \& Durk, G. (eds.). (2009). Linguistic landscape: Expanding the scenery. New York: Routledge.

Wan, Q. (2016). Errors and Solutions of C-E Translation on Tourism Spots Signs. Cross-Cultural Communication, 12(12), 14-19.

Wang, C. Y. (2009). Reader-Oriented Translation of Chinese Public Signs Based on the Communicative Translation Theory. Journal of Xiamen University of Technology, 3, 103-106.

Yang, Q. H. (2005). On English Translation of Public Signs in Chinese. Chinese Translators Journal, 6, 43-46.

Zhang, Z., \& Peng, F. S. (2015). A Coursebook of Chinese and Western Translation Theories. Beijing: Tsinghua University Press.

\section{Copyright Disclaimer}

Copyright for this article is retained by the author(s), with first publication rights granted to the journal.

This is an open-access article distributed under the terms and conditions of the Creative Commons Attribution license (http://creativecommons.org/licenses/by/3.0/). 